Article

\title{
Experimental Test on Nonuniform Deformation in the Tilted Strata of a Deep Coal Mine
}

\author{
Hai Wu ${ }^{1,2, * \mathbb{C}}$, Qian Jia ${ }^{2}$, Weijun Wang ${ }^{2}$, Nong Zhang ${ }^{3,4}$ and Yiming Zhao ${ }^{4}$ \\ 1 Work Safety Key Lab on Prevention and Control of Gas and Roof Disasters for Southern Goal Mines, \\ Hunan University of Science and Technology, Xiangtan 411201, China \\ 2 School of Resources, Environment and Safety Engineering, Hunan University of Science and Technology, \\ Xiangtan 411201, China; gj_wkjq@163.com (Q.J.); wjwang@hnust.edu.cn (W.W.) \\ 3 School of Resources, Academy of Interdisciplinarity \& Application, Jiangsu Normal University, \\ Xuzhou 221116, China; zhangnong@126.com \\ 4 School of Mines, Key Laboratory of Deep Coal Resource Mining, Ministry of Education, China University of \\ Mining and Technology, Xuzhou 221008, China; zhaoyiming001@163.com \\ * Correspondence: wuhai@hnust.edu.cn
}

check for updates

Citation: Wu, H.; Jia, Q.; Wang, W.; Zhong, N.; Zhao, Y. Experimental Test on Nonuniform Deformation in the Tilted Strata of a Deep Coal Mine. Sustainability 2021, 13, 13280. https://doi.org/10.3390/ su132313280

Academic Editors:

Mahdi Hasanipanah, Danial Jahed Armaghani and Jian Zhou

Received: 24 October 2021

Accepted: 27 November 2021

Published: 30 November 2021

Publisher's Note: MDPI stays neutral with regard to jurisdictional claims in published maps and institutional affiliations.

Copyright: (c) 2021 by the authors. Licensee MDPI, Basel, Switzerland. This article is an open access article distributed under the terms and conditions of the Creative Commons Attribution (CC BY) license (https:/ / creativecommons.org/licenses/by/ $4.0 /)$.

\begin{abstract}
Taking a deep-mine horizontal roadway in inclined strata as our research object, the true triaxial simulation technique was used to establish a model of the inclined strata and carry out high-stress triaxial loading experiments. The experimental results show that the deformation of surrounding rock in the roadway presents heterogeneous deformation characteristics in time and space: the deformation of the surrounding rock at different positions of the roadway occurs at different times. In the process of deformation of the surrounding rock, deformation and failure occur at the floor of the roadway first, followed by the lower shoulder-angle of the roadway, and finally the rest of the roadway. The deformation amount in the various areas is different. The floor heave deformation of the roadway floor is the greatest and shows obvious left-right asymmetry. The deformation of the higher side is greater than that of the lower side. The model disassembly shows that the development of cracks in the surrounding rock is characterized by more cracks on the higher side and fewer cracks on the lower side but shows larger cracks across the width. The experimental results of high-stress deformation of the surrounding rock are helpful in the design of supports, the reinforcement scheme, and the parameter optimization of roadways in high-stress-inclined rock, and to improve the stability control of deep high-stress roadways.
\end{abstract}

Keywords: tilted strata; roadway; nonuniform deformation; physical simulation

\section{Introduction}

More than $50 \%$ of the development and mining roadways in China's coal mines pass through inclined rock strata, making the surrounding rock of the roadway prone to asymmetric deformation. With any increase in the buried depth of roadway, the deformation of roadway-surrounding rock of inclined rock strata increases, and stability control becomes very challenging. Therefore, it is imperative to investigate the deformation characteristics of roadway-surrounding rock in the case of deep inclined rock strata. Many factors are known to influence the stability of roadways; in general, they include: overburden, coal seam thickness, geological conditions, the presence of unfavorable structures, clay minerals, mining methods, and, most importantly, the dip angle of the coal seams. Due to the importance of this topic, there has been a great deal of research on the deformation laws of roadways with steep dip angles. For example, Yu et al. [1] established a mechanical model of a coal body on two sides of a mining roadway under abutment pressure and analyzed the basic distribution law of interface stress between the coal body and the roof and floor, as well as the axial force of the coal body. Zhang et al. [2] researched asymmetric deformation and the failure mechanisms of roadway-surrounding rock in a large dip coal seam; they 
proposed asymmetric coupling support countermeasures for key parts of the surrounding rock of the roadway in a large dip coal seam. Li et al. [3] established a mechanical model for the plastic zone of a coal seam and believed that with the increase in width of the supporting structure, the width of the plastic zone of the coal seam decreases linearly. The friction angle in the supporting structure increases and the plastic zone width of the coal seam decreases. Zhang et al. [4] proposed the technical principle of constructing an integral closed support with an anchor bolt, anchor cable, grouting, and other active support as the main body, supplemented by structural reinforcement. Zhang et al. [5] analyzed the deformation characteristics of inclined rock drift using different support methods and grasped the distribution characteristics of cracks in roadway-surrounding rock when under plane strain conditions. Zhang et al. [6] used the new, combined three-dimensional geomechanical model testbed in their research and showed that the range of the partition fracture of the cavern is related to the shape and size of the cavern; the larger the size of the cavern, the larger the partition fracture range. Guo et al. [7] used a numerical simulation to analyze the influence of the lateral pressure coefficient of the surrounding rock pressure on roadway deformation and its influence on the stress distribution around it. Xue [8] conducted similar simulation research on the deformation characteristics of horizontal roadways that are without support. The results show that the roof force comes from the dislocation of the old roof, and the floor force comes from the weight of the overlying rock and stress from mining operations. The force of the coal beside the roadway comes from energy release and the dilatancy deformation stress undermining conditions. Liu et al. [9] analyzed the size effect on tunnels surrounding rock deformation. The relationship between bending deformation and a section of the laminated roof is pointed out from the point of view of the simply supported beam. Sun et al. [10] numerically simulated the asymmetric deformation of a roadway in inclined strata and proposed the control countermeasures of asymmetric coupling support. Zhang et al. [11] adopted a reinforcement control strategy for the deep roadway in the Qishan mining area, which greatly improved the stability of the surrounding rock of the roadway. Bao et al. [12] established the model of a layered roadway in a layered rock mass using finite element software, ANSYS, and analyzed the deformation characteristics of a layered roadway. Wang et al. [13] proposed the idea of reinforcing two sides of a deep roadway to control floor heave and verified that reinforcing two sides can control the floor heave of a deep roadway to a certain extent. Fan et al. [14] used acoustic emission to research the large-scale three-dimensional physical similarity simulation experimental model of roadway shield excavation and established the law of acoustic emission regarding surrounding rock failure during excavation. Chen et al. [15] found that under the conditions of shallow-buried hydrostatic pressure, the surrounding rock of the roadway showed the characteristics of "shallow tensile strain and deep zero strain". Gao et al. [16] researched the mechanical deformation behavior characteristics of an in-situ rock mass under high stress. Zhang et al. [17] researched the mechanical behavior of the progressive failure of sandstone under true triaxial conditions. Yin et al. [18,19] researched the stability and plastic zone characteristics of borehole-surrounding rock under true triaxial stress. Wang et al. [20] conducted an experimental study of the deformation and failure of a fractured rock mass around the roadway, under true triaxial loading and unloading. Through Flac3D numerical simulation, H. Zhang et al. [21] found that under seepage, especially with an increase in water head and porosity, the mechanical properties of the surrounding rock were weak, and the deformation was large, which was consistent with the field observation. X.J. Yang et al. [22] researched the support problem of deep soft rock roadway with large deformation. The deformation, stress and crack propagation characteristics of the roadway are revealed by simulating the failure modes of the unsupported roadway and the initially supported roadway. $\mathrm{M}$. Li et al. [23] researched an innovative mining method for a thick separated seam. The coal seam is divided into different zones, according to the thickness of the rock separation, and three mining schemes comprising full coal-seam mining, combined backfill caving mining (CMBC), and lowering-height mining are used to mine the three zones. D.D. Qin et al. [24] researched the surrounding 
rock structure distribution characteristics of this kind of roadway by combining theoretical analysis and numerical simulation. Based on the control effect of different supporting modes on the surrounding rock structure, a reinforcement scheme for a deep dynamic soft rock roadway is proposed and applied. The problem of deformation of a rock mass with a layered structure has already been analyzed by many researchers, but so far, no models have been studied in the macro scale under three-axial conditions. In these studies, there is a lack of research on the internal failure of roadway-surrounding rock, so the research cannot fully explain the essential mechanism of the occurrence of the inhomogeneous deformation law of inclined layers in the rock surrounding a roadway. The purpose of this paper is to research the characteristics and deformation mechanism of the inhomogeneous deformation of a horizontal roadway in deep inclined strata via true triaxial experiment and explain the deformation and aging characteristics of the surrounding rock and the failure mechanism within the surrounding rock.

\section{Similar Simulation Engineering Background Introduction of Experimental Equipment}

The experimental study used the Jiangxi Qujiang Mining Company -850 East Roadway Extension as the engineering background of a similar simulation. The -850 East Roadway is arranged along a strike in the floor strata of a coal seam; the strata are generally monocline, with an inclination of $15^{\circ}$. The roadway of the East Roadway Extension is cut through whole rock, and the lithology is grayish-black siltstone with thin to medium-thick bedding. It is interbedded with thin-layered mudstone and a fine sandstone belt containing a small number of siderite nodules, fossilized plant rhizome, joint development, and calcium clay cementation of medium and low hardness. The cross-section of the roadway is a straightwalled semicircular arch with a width of $4.4 \mathrm{~m}$ and a height of $3.5 \mathrm{~m}$. The supporting method is of a combined support with an anchor rod, anchor net, ladder beam, shotcrete, and anchor cable, and the row distance between the bolts is $700 \times 700 \mathrm{~mm}$. For spraying, 425 ordinary Portland cement and pure river sand are used, and the thickness of the spraying layer is $100 \mathrm{~mm}$. Three single anchor cables of $6.3 \mathrm{~m}$ at intervals of $1.6 \mathrm{~m}$ were arranged in the middle of the two shoulders and the arch of the roadway. The field investigation showed that the deformation of the surrounding rock in the east roadway exhibits the following characteristics. (1) The roof of the roadway was asymmetrically deformed, and continuous failure cracks along the axial direction appeared at the right shoulder angle of the roadway roof, while the left shoulder angle was relatively complete, as shown in Figure 1a. (2) The asymmetric deformation from floor heave is manifested thus: the floor heave is greater on the left side of the roadway than on the right side, and the maximum floor heave is $0.8 \mathrm{~m}$ to the left of the line of the roadway, as shown in Figure $1 \mathrm{~b}$. (3) The results of observation via boreholes on both sides of the roadway show that the development of internal fractures in both sides of the roadway is asymmetrical, and that there are more fractures in the rock mass to the left side of the roadway than to the right side of the roadway (for more details, see [25]). 


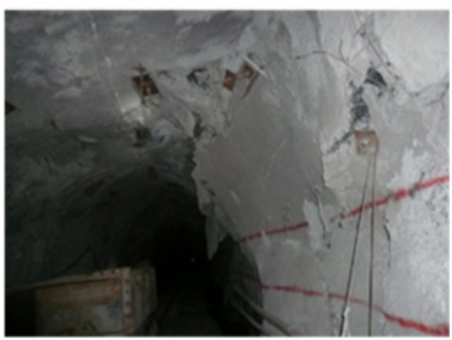

(a)

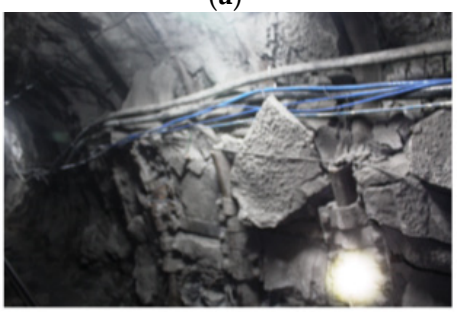

(c)

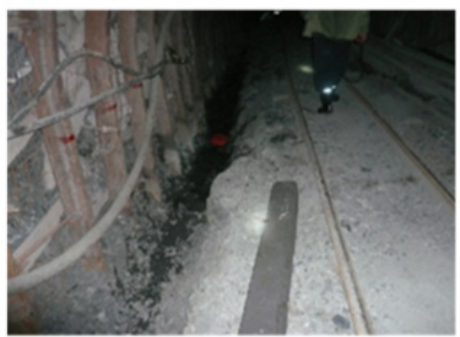

(b)

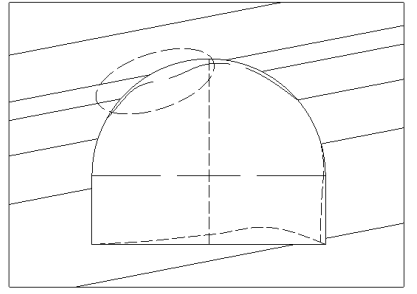

(d)

Figure 1. Asymmetrical deformation of the roadway and its schematic diagram. (a) Failures in part of the right roof-side wall of the roadway. (b) Floor upheaval is severe. (c) Roadway failure at the lower side. (d) Sketch of the non-uniform deformation of the roadway.

\section{Experimental Model Making and Experimental Scheme}

\subsection{Introduction of Experimental Equipment}

The $20 \mathrm{MPa}$ "three directions and on five sides" vertical main loading experimental system is composed of four parts: the host system, the electro-hydraulic servo system, the measurement and control system, and the sample preparation system, realizing independent active loading in " 3 directions and on 5 surfaces" for a large sample $(1000 \times 1000 \times 400 \mathrm{~mm})$ (Figure 2). The loading size, speed, and load-holding time of each surface can be adjusted independently, and the maximum loading stress of each surface is $20 \mathrm{MPa}$. The system adopts a separate design for test block fabrication and the experimental loading processes are independent of each other. Multiple test blocks with different parameters can be prefabricated in advance and multiple loading experiments can be carried out continuously. The equipment can be used to complete the uniaxial, biaxial, and triaxial compression test, simulating the high-stress excavation of a roadway and of a roadway affected by mining. The characteristics of timeliness under high stress were observed by simulating the high-stress loading of a rock mass. The time-effectiveness characteristics of simulated rock mass alter under high stress and simulate the dynamic characteristics of rock mass after multiple loading and unloading in a complex stress environment. The model test space's length $\times$ width $\times$ height $=1000 \times 1000 \times 400 \mathrm{~mm}$. In the vertical direction, the loading surface's length $\times$ width $=1000 \times 1000 \mathrm{~mm}$; in the horizontal direction, the four surfaces' length $\times$ width $=1000 \times 400 \mathrm{~mm}$. The force frame diagram of the test block is shown in Figure 3. The displacement resolution of the equipment is $0.007 \mathrm{~mm}$. The relative error of displacement indication and the relative error of the test pressure indication is $\leq \pm 0.5 \%$.
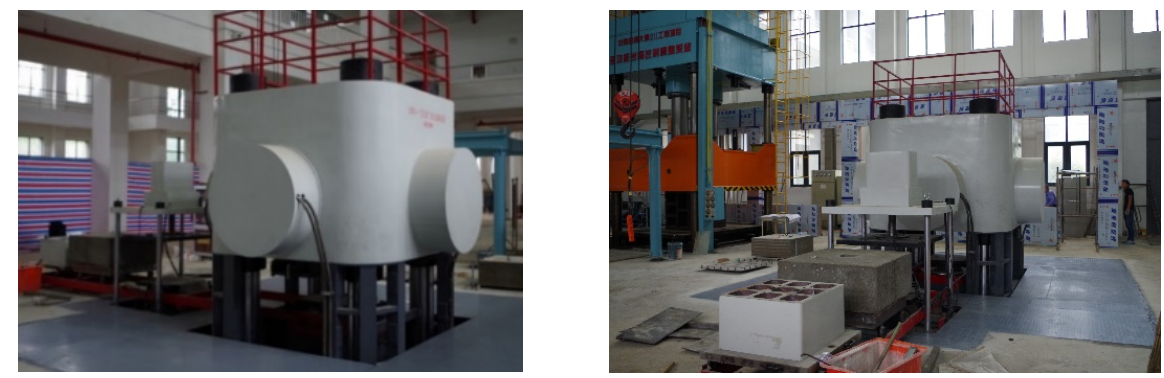

Figure 2. The true triaxial simulation experiment system. 


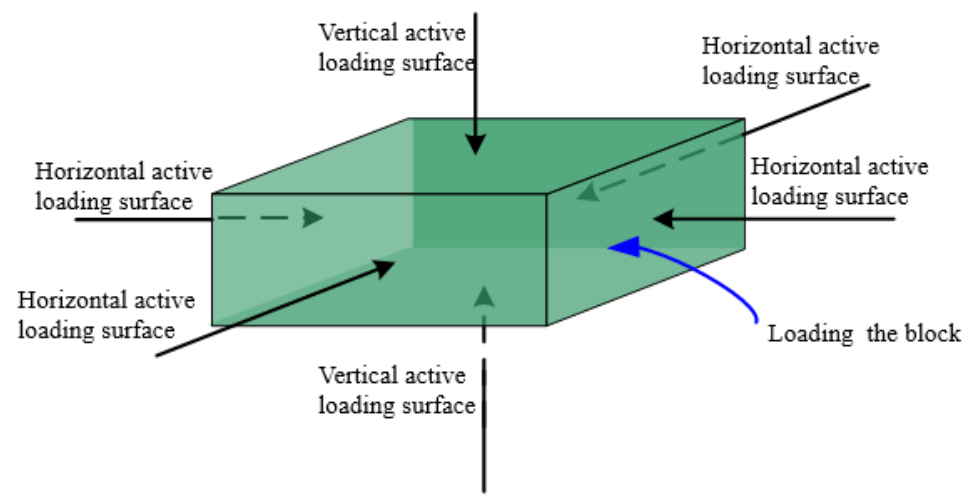

Figure 3. Force frame diagram of the test block.

\subsection{Experimental Model-Making Process}

(1) Equivalent material selection-similar equivalent materials to the rock in question are made of cement, gypsum, and river sand. To master the mechanical properties of similar materials, different overproportioning samples are made and uniaxial compression tests are carried out. To improve the ductility of similar materials, a set amount of the mortar fiber used in construction is added. The fiber is made of polypropylene material, the fiber length is $12 \mathrm{~mm}$, and the addition amount is $5 \mathrm{~kg}$ per cubic meter. We added a certain amount of borax as retarder; the amount of borax is $5 \%$ of the water used. Ten groups of test blocks were made using the mold for standard mortar test blocks, with three in each group. The sample size of the small test block is $70.7 \mathrm{~mm} \times 70.7 \mathrm{~mm} \times 70.7 \mathrm{~mm}$. The mold was removed 3 days after the completion of production, and the compressive strength of the test blocks was tested 10 days after drying. Figure 4 shows the No. 3 test block (473 is the ratio number of sand cement gypsum, and the dosage ratio is sand: cement: gypsum is 40:7:3) in the uniaxial compressive test, and Figure 5 shows the compressive strength curve of the test block.

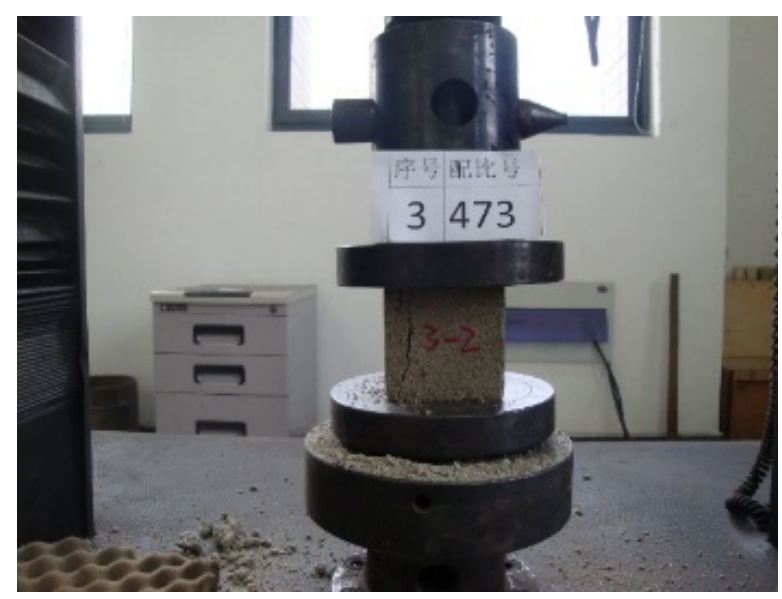

Figure 4. Uniaxial compressive test of the block. (“3": 3 shows the No.3 test block; “序号”: the serial number; “473”: 473 is the ratio number of sand cement gypsum; “配比号”: Material dosage ratio).

Figure 5 shows that the uniaxial compressive strength of the material reaches $3.8 \mathrm{MPa}$. Considering that the strength of the test block will be improved to a certain extent under the conditions of triaxial compression, a physically similar material with a ratio number of 473 was selected for similarity simulation. There is a small fluctuation in the rising stage of the curve, which is a stage of stress adjustment (see Table 1 for the specific parameters of the material). 


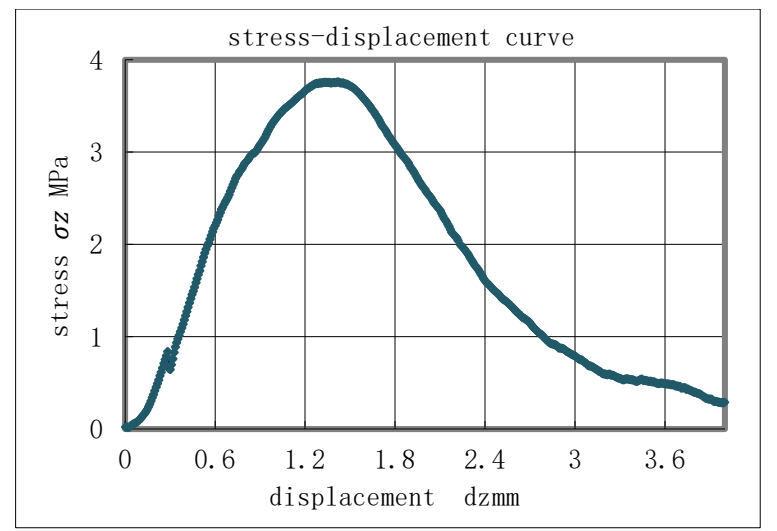

Figure 5. Typical stress $\sigma z$-displacement $\mathrm{dz}$ characteristics of the sample under uniaxial compression.

Table 1. Physical modeling material parameter.

\begin{tabular}{ccc}
\hline Material Number & Density, $\mathbf{g} / \mathrm{cm}^{3}$ & Compressive Strength, MPa \\
\hline 473 & 2.20 & 2.77 \\
\hline
\end{tabular}

(2) Determination of model scale and roadway size-correlation studies of similar simulations and numerical models show that when the ratio of model excavation radius to boundary distance is $1: 5$, the experimental error is about $6 \%$. The maximum size of the similar simulation test block is width $\times$ height $=1000 \mathrm{~mm} \times 1000 \mathrm{~mm}$, so the ratio of roadway excavation radius and boundary distance is 90:500 $=0.9: 5$, and the roadway excavation radius is set at $90 \mathrm{~mm}$.

(3) Preparation of a similar simulation test block-(i) According to the roadway position, rock stratum histogram, and model scale, the physical structure diagram of a similar simulation test block was made. (ii) Fix the physical structure drawing on the base of the test block to make the model and cover it with a thin film. Install the test block to make the mold. (iii) According to the physical structure diagram, using the selected similarity ratio, calculate the number of similar materials required by each layer of rock mass, mix and stir these similar materials, and layer the model. Special attention should be paid to the uniformity of the model density during model layering. (iv) The manufactured test block and the mold are sent together to the pressing platform for prepress to ensure that each surface is flat and parallel. (v) After the preloading is completed, the test block would be dried for 2-3 days, and the roadway excavation and surface leveling would be carried out according to the design requirements, as shown in Figure 6.
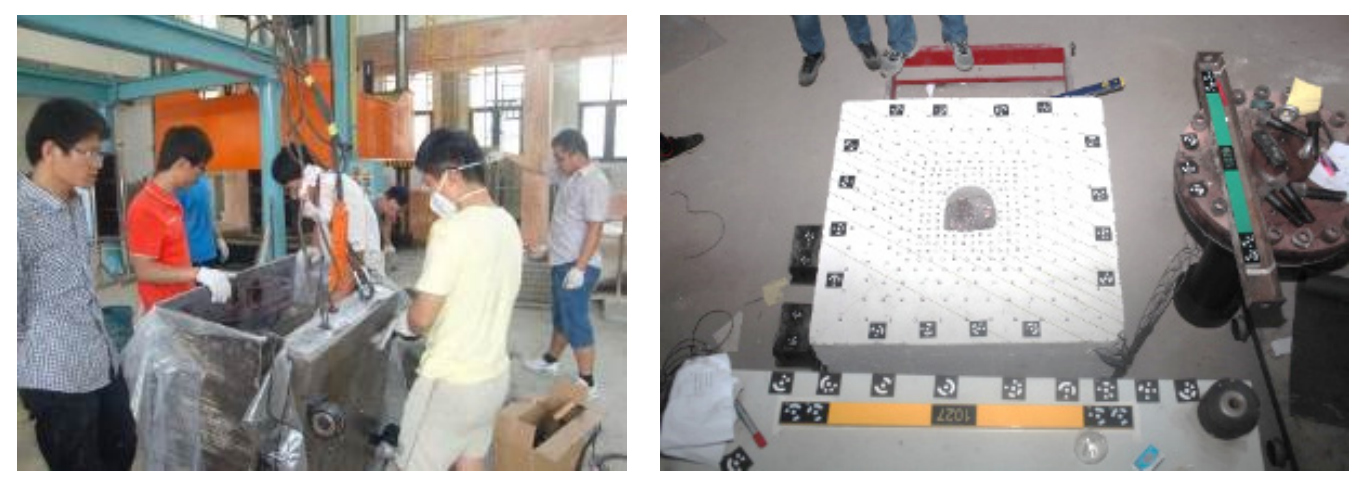

Figure 6. Production of a similar simulation sample block model.

\subsection{Experimental Data Acquisition}

Photogrammetry was used to measure the deformation and displacement of the surrounding rock. The layout of the monitoring points for the photogrammetric displacement 
of the surrounding rock is shown in Figure 7. To further understand the mechanism of the deformation and failure of the surrounding rock, the crack development in the surrounding rock of the roadway was statistically analyzed when the model was disassembled.

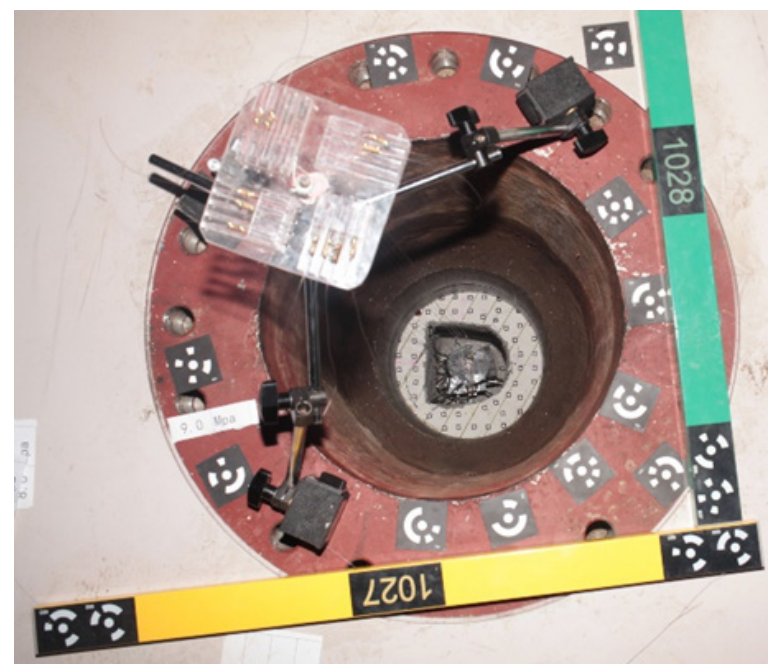

Figure 7. Displacement monitoring point layout.

\subsection{Experimental Stress-Loading Scheme}

Stress loading is carried out in two steps: (1) The vertical, front and rear, and left and right stress in synchronized loading increased from $0 \mathrm{MPa}$ to $3 \mathrm{MPa}$. This comprises the stress adjustment stage of the experimental equipment and test block. (2) When the stress of the surrounding rock is greater than $3 \mathrm{MPa}$, the stress increases by $0.2 \mathrm{MPa}$ each time, then the stress remains unchanged for $3 \mathrm{~min}$, and then the stress continues to increase by 0.2 MPa. The real stress loading curve is shown in Figure 8.

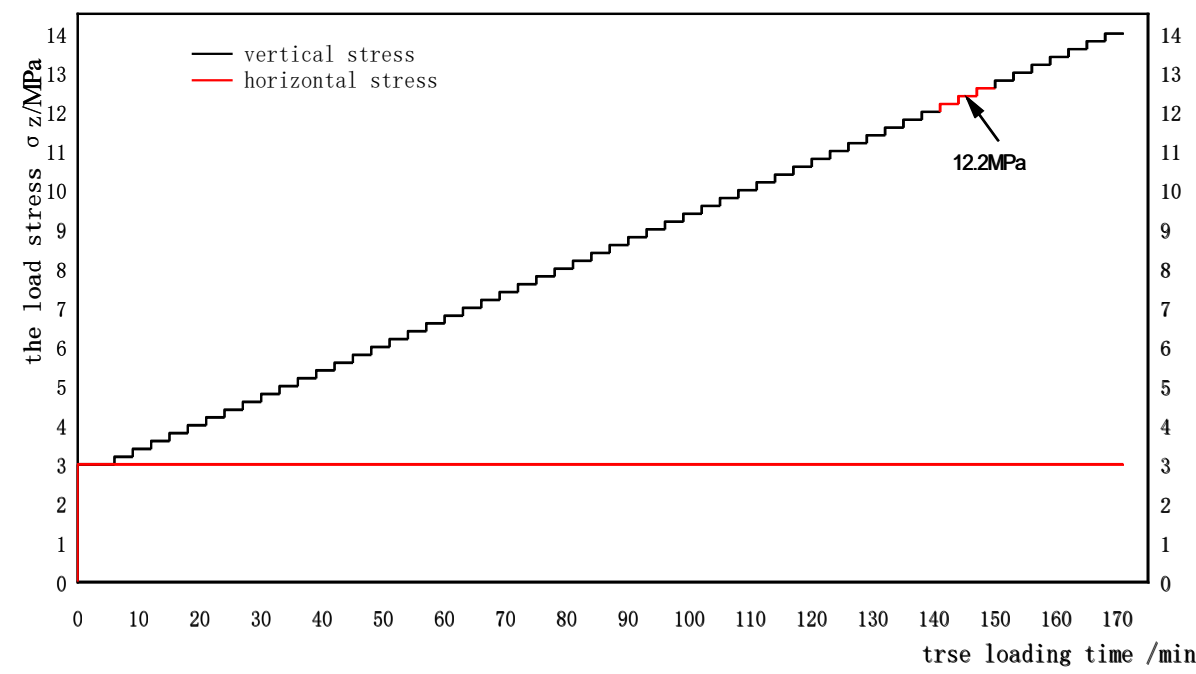

Figure 8. Stress curve of experimental loading time.

\section{Analysis of Asymmetric Deformation Characteristics of Roadway-Surrounding Rock}

\subsection{Characteristics of Roadway Surrounding Rock Deformation}

With an increase in stress, the surrounding rock of the roadway gradually deforms and becomes unstable until it is destroyed. Photographic monitoring was carried out to obtain a comparative analysis diagram of roadway surface deformation at different stress stages (Figure 3), which shows that: (1) when stress on the surrounding rock is low (the surrounding rock stress is less than $6 \mathrm{MPa}$ ), the surrounding rock does not demonstrate 
obvious deformation, as shown in Figure 9a,b. (2) When the surrounding rock stress increased to $6 \mathrm{MPa}$ (Figure 9c), relatively obvious transverse cracks first appeared at the bottom corner of the roadway, on the lower side. With the increase in stress in the surrounding rock, new cracks were constantly being generated in the surrounding rock at the bottom corner of the lower side (Figure 9d). (3) Figure 9e,f shows that when the stress of the surrounding rock increases to $9 \mathrm{MPa}$ below the higher side of the roadway, an interlayer dislocation deformation of the different rock strata occurs along the direction of bedding, and the floor of the roadway shows the phenomenon known as bed separation. At the same time, there are cracks on both sides of the roadway arc at the lower shoulder angle and at the tangent of the rock layer. As the stress level of the surrounding rock continues to increase, the floor heave of the roadway increases continuously. Layered slip and bending fracture occurred in the in-floor strata; the surface of the roadway showed asymmetrical floor heave on both sides, and the cracks on both sides of the low shoulder angle increased continuously. (4) Figure $9 \mathrm{~g}$ shows that when the surrounding rock stress is $11.6 \mathrm{MPa}$, substantial deformation and failure occur in the surrounding rock and floor heave occurs in the floor of the roadway. Both sides of the low shoulder angle were damaged along the rock boundary. When the stress loading reaches $12.2 \mathrm{MPa}$, the roadway suddenly fails. The deformation of the surrounding rock of the roadway in a similar model and the in-field measurements all show that the floor heave of the roadway-surrounding rock is asymmetric and deformation on both sides of the low shoulder angle shows that it is easy to damage the relative integrity of the high surface.

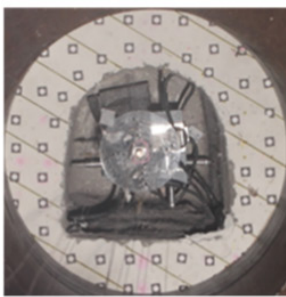

(a) $3 \mathrm{MPa}$

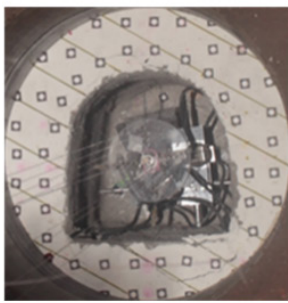

(f) $9 \mathrm{MPa}$

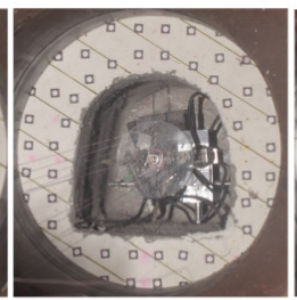

(b) $5 \mathrm{MPa}$

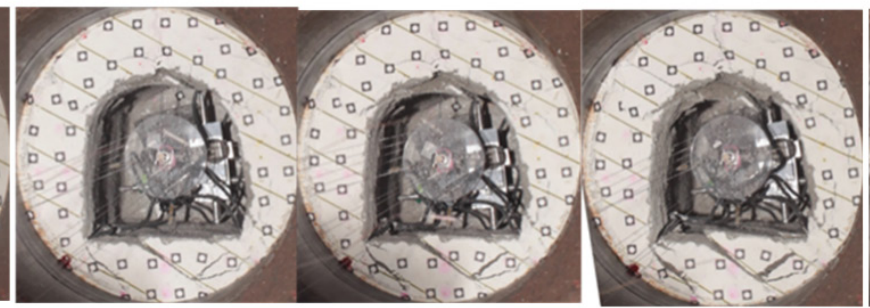

(g) $10 \mathrm{MPa}$

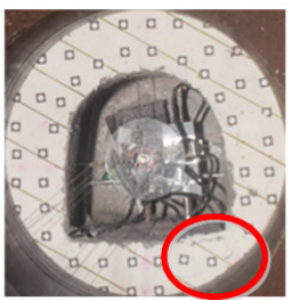

(c) $6 \mathrm{MPa}$

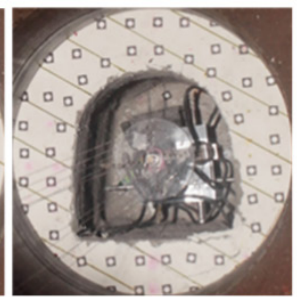

(d) $7 \mathrm{MPa}$

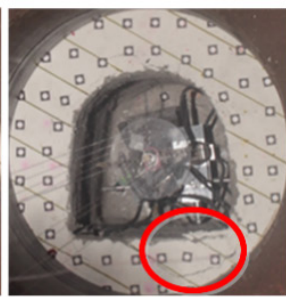

(e) $8 \mathrm{MPa}$

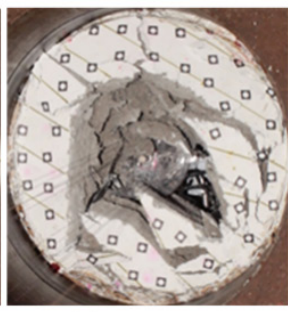

(j) $12.2 \mathrm{MPa}$

Figure 9. Surface deformation of the roadway.

\subsection{Spacial Deformation Displacement Distribution Characteristics of a Roadway}

The coordinate data from monitoring points before and after the large deformation and failure of the roadway-surrounding rock were extracted by photogrammetry. The mapping software was used to obtain the position changes of monitoring points on the surrounding rock surface before and after the deformation and failure of the model roadway (see Figure 10).

Analysis of the positions before and after the monitoring points shows that the deformation characteristics of the surrounding rock can be analyzed in four regions, namely, the higher side of the roadway, the lower side of the roadway, the floor, and the roof. (1) The surrounding rock monitoring points within the higher side of the roadway move towards the center and floor of the roadway. With the increase in the distance between the monitoring point and the floor, the horizontal and vertical displacements of the monitoring point decrease gradually. (2) The monitoring points on the lower side of the roadway move 
towards the center and floor of the roadway. The horizontal displacement increases with the increase in the distance from the monitoring point to the floor height and reaches its maximum value at the shoulder angle. The vertical displacement at the bottom angle of the lower side is upward and gradually decreases with the increase in the distance from the monitoring point to the floor height. The vertical displacement at the shoulder angle is downward, and there is zero displacement of the point at the low shoulder angle. (3) The vertical displacement of the monitoring points on the floor of the roadway all point to the center direction of the roadway, and the displacement on the higher side is large, while the displacement on the lower side is relatively small. On the other hand, the horizontal displacements are in opposite directions, with the center of the roadway floor as the boundary, all pointing to the center of the roadway floor; the displacement on the higher side is greater than that on the lower side. The floor deformation is the same as in the field reality, which is the area with the largest roadway deformation and the area where deformation and failure occur first. (4) The horizontal displacement of the monitoring points on the roof of the roadway all point to the higher side, and the horizontal displacement on the higher side is greater than that on the lower side. The vertical displacement showed the minimum value at the higher side shoulder-angle and the maximum at the lower side shoulder angle.
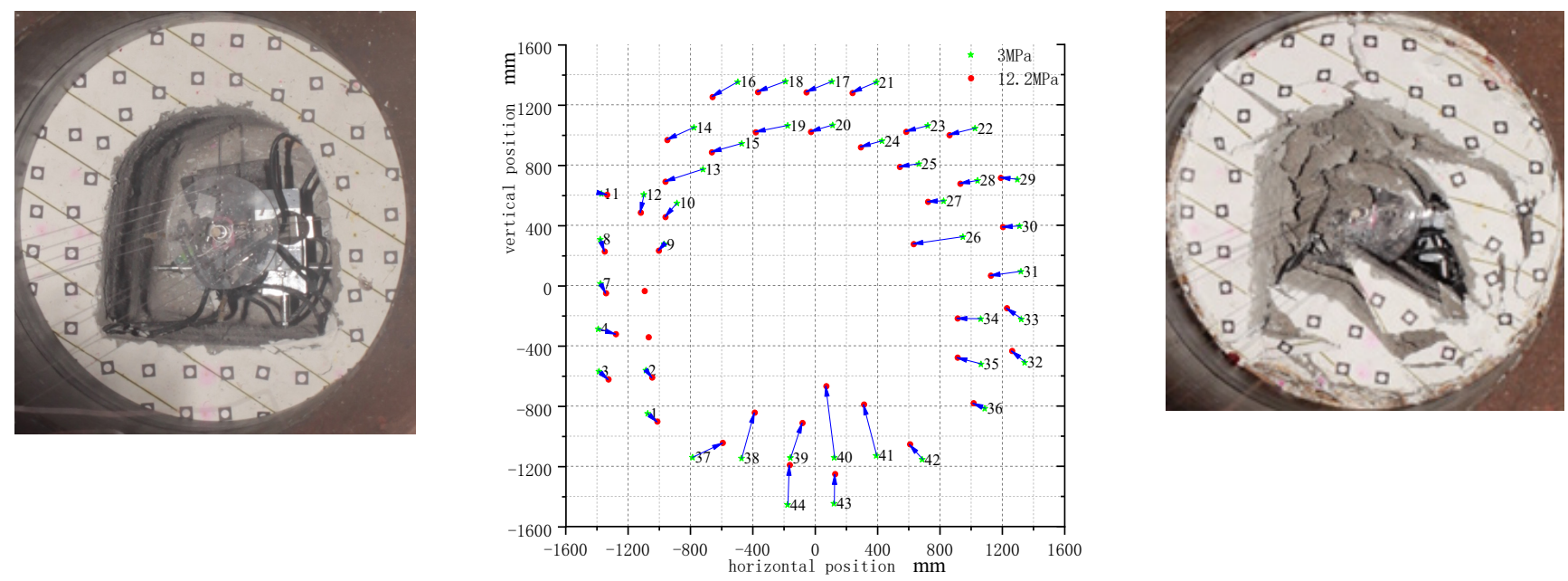

Figure 10. Comparison diagram of monitoring points before and after roadway failure.

The displacement data of monitoring points on the roadway surface are compared and analyzed in order to further research the heterogeneity of the displacement of surrounding rock deformation in the inclined roadway. The positions of specific monitoring points and the magnitude of displacement are shown in Table 2. After summing up the displacement of the monitoring points on the roadway surface, the average value is obtained, namely:

$$
d_{\text {average }}=\frac{\sum_{1}^{n} d_{i}}{n}
$$

where $d_{i}$ is the displacement of the " $i$ " monitoring point; " $n$ " is the number of monitoring points. In terms of the situation of $\boldsymbol{d}_{\text {average }}<\boldsymbol{d}_{\boldsymbol{i}}$ in each partition, the statistical results show that: (1) The deformation at the monitoring point of the roadway floor surface deformation is the largest. The number of monitoring sites exceeding the average deformation was the largest here, at 4. (2) There are two monitoring points where the deformation of the roadway roof exceeds the average value. (3) There was one monitoring point where the deformation of the lower side of the roadway exceeded the average value. (4) The deformation of no monitoring point in the higher-level wall of the roadway exceeds the average value. Therefore, the deformation of the surrounding rock of the roadway shows heterogeneous characteristics: floor $>$ roof $>$ lower side $>$ higher side. 
Table 2. Comparative analysis of the displacement of monitoring points on the roadway surface.

\begin{tabular}{|c|c|c|c|c|c|c|c|c|}
\hline No. & Location & $\begin{array}{l}\text { Displacement } \\
\text { (cm) }\end{array}$ & Number & Location & $\begin{array}{l}\text { Displacement } \\
\text { (cm) }\end{array}$ & Number & Location & $\begin{array}{c}\text { Displacement } \\
\text { (cm) }\end{array}$ \\
\hline 1 & high-level wall & 1.69 & 19 & roof & 4.53 & 36 & \multirow{2}{*}{$\begin{array}{l}\text { low-level wall } \\
\text { floor }\end{array}$} & 1.80 \\
\hline 2 & high-level wall & 1.30 & 20 & roof & 3.19 & 37 & & 4.46 \\
\hline 5 & high-level wall & 1.24 & 24 & roof & 3.12 & 38 & floor & 6.54 \\
\hline 6 & high-level wall & 1.13 & 25 & roof & 2.75 & 39 & floor & 5.04 \\
\hline 9 & high-level wall & 1.24 & 26 & low-level wall & 6.88 & 40 & floor & 10.02 \\
\hline 10 & high-level wall & 2.54 & 27 & low-level wall & 2.26 & 41 & floor & 7.31 \\
\hline 13 & roof & 5.46 & 34 & low-level wall & 3.30 & 42 & floor & 2.71 \\
\hline 15 & roof & 4.32 & 35 & low-level wall & 3.45 & & & \\
\hline
\end{tabular}

Note: boxes with a color background highlight areas where the displacement is greater than the mean value.

\subsection{Analysis of Internal Crack Development Characteristics of Roadway-Surrounding Rock}

After the experiment, the observation results showed that some joint opening and slippage occurred along the bedding plane of the model, and the specific distribution is shown in the Figure 11.

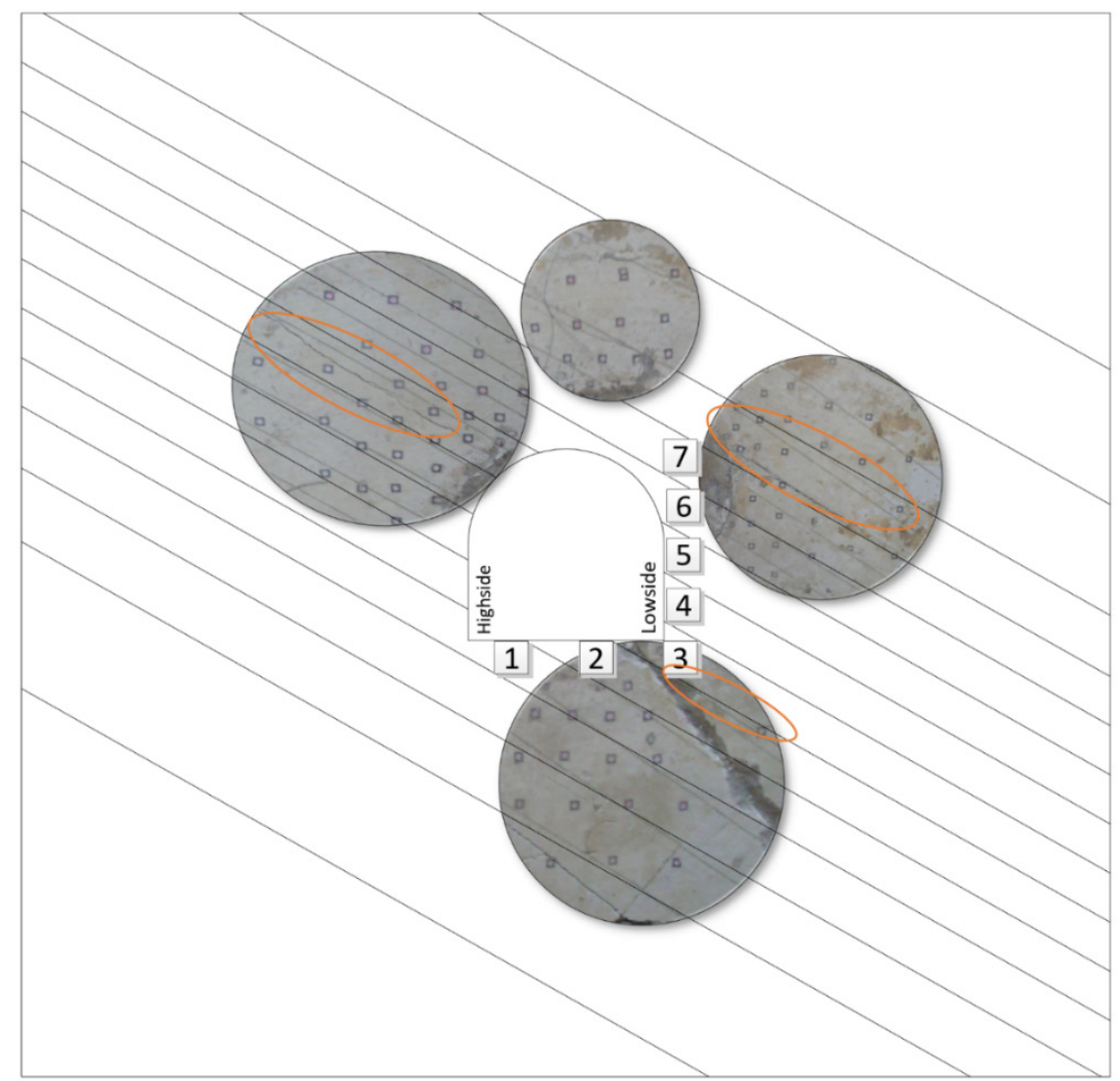

Figure 11. Surface fractures-position on the model.

The model was further disassembled along the inner layer to examine the internal damage conditions of the surrounding rock of the roadway at different layers, as shown in Figures 11-13. The development characteristics of internal cracks after model failure can thus be obtained. The proportions of the pictures and photos are the same, with the numbers 1-7 representing the different rock layers. These pictures were taken from the outside of the model and cracks appeared, so they were shown in the model for comparison. 

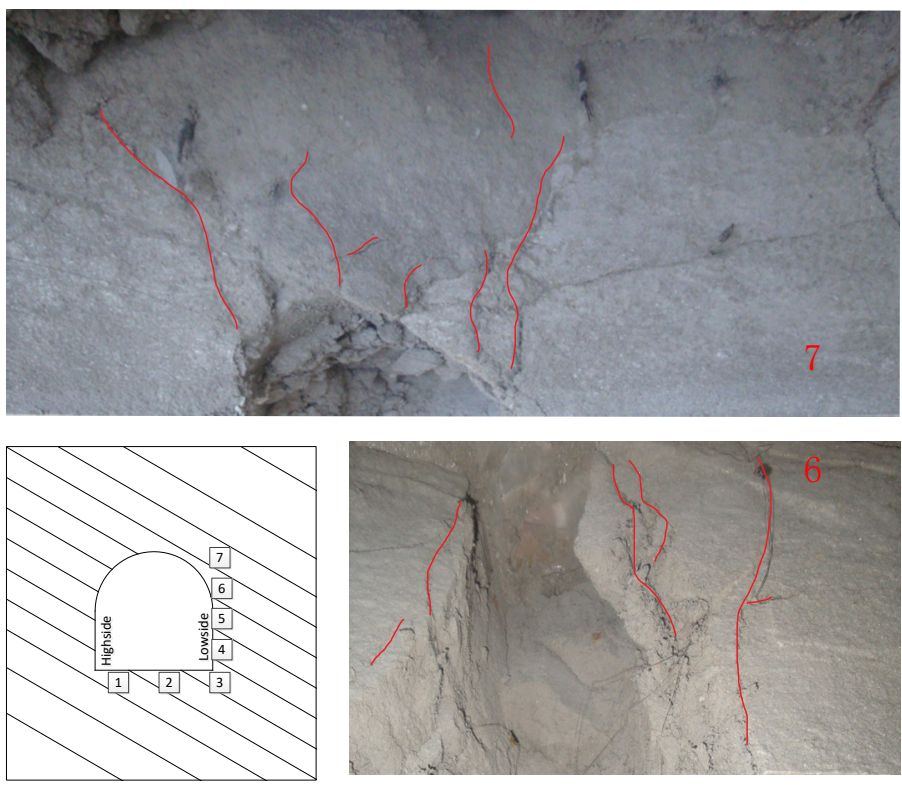

Figure 12. Inner failure of the surrounding rock of the roadway.

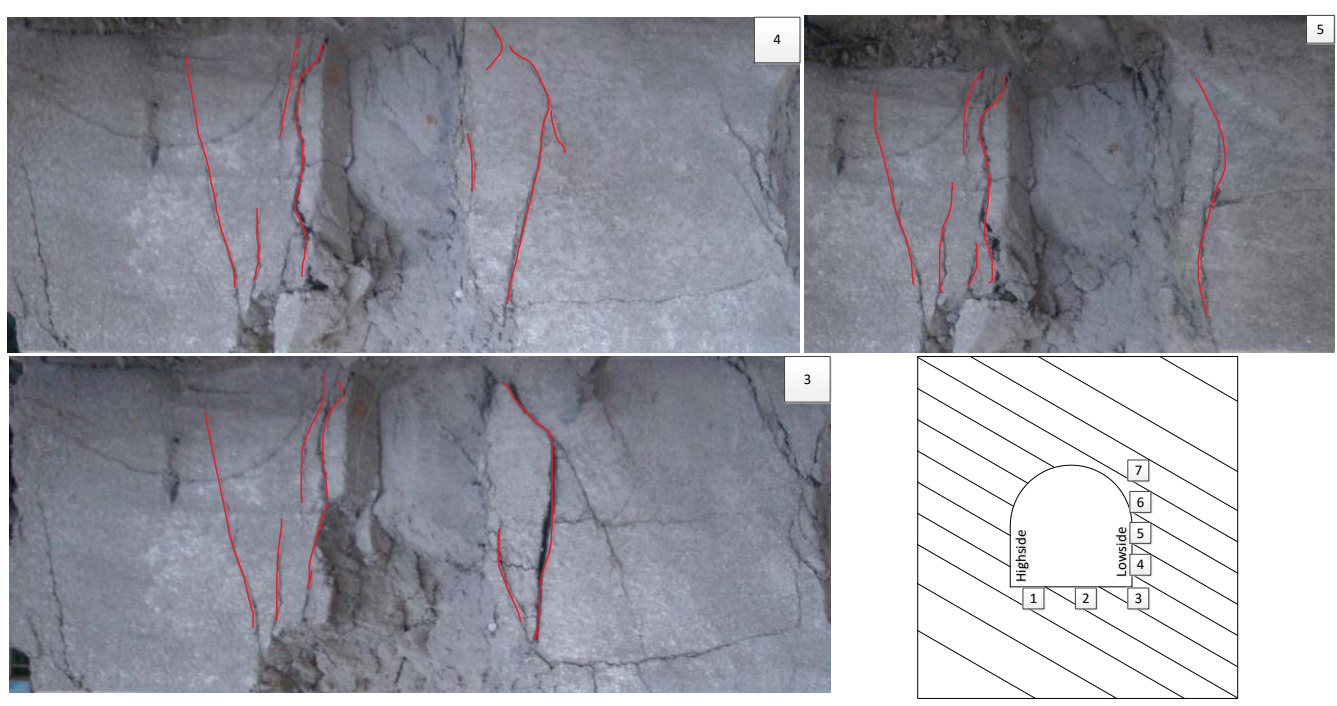

Figure 13. Failure structure of the surrounding rocks of two sides of the roadway.

(1) Failure characteristics of the surrounding rock in the roadway roof (see Figure 11) Under the scenario of a $30^{\circ}$ inclination, the failure of the surrounding rock in the roadway roof is mainly concentrated in a position near the shoulder angle of the roadway roof, and the tangent point between the rock layer and roadway surface is at the center. From the direction of crack development, most of the crack directions run parallel to the direction of the roadway. From the point of view of the number of cracks, the number of cracks on the higher side is less than that on the lower side.

(2) Characteristics of crack development on two sides of the roadway-Figure 12 shows that the cracks in the higher and lower sides of the roadway show obvious asymmetry, which is mainly manifested in the fact that the cracks in the higher and lower sides are mainly parallel to the direction of the roadway. The number of internal cracks in the higher-wall rock is more than that in the lower-side rock, but the width of the cracks in the higher-side rock is smaller than that in the lower-side rock. As for the crack location, the crack at the lower-side shoulder angle of the roadway was close to the surface of the roadway, and the depth of the crack location increased with the decrease in height. Higher-side cracks are mainly concentrated on the surface of the roadway. In terms of crack 
width, the crack width near the lower-side surface is smaller, and the crack width at the deeper side is larger. The width of the internal crack on the higher side decreases gradually from the outside to the inside.

(3) Characteristics of crack development in roadway floor-Figure 13 shows that the floor of the roadway is the area with the largest deformation of surrounding rock, and the rock strata in the middle of the floor of the roadway are fractured and rotated. There is an obvious relative sliding and opening phenomenon between the different strata on the floor. The surrounding rock at the bottom corner of the higher side is broken in pieces, and the broken zone extends along the direction of the roadway. A large number of cracks appeared in the deeper rock mass in the floor plate of the lower side. From the perspective of crack distribution, the number of cracks on the lower side was greater than that on the higher side, as shown in Figure 13.

(4) Overall development characteristics of internal cracks in roadway surrounding rock-According to Figures 11-14, obtained from the model disassembly, a sketch of the crack development in the surrounding rock of the roadway was drawn, as shown in Figure 15. The crack development showed asymmetry, with more cracks on the higher side and fewer cracks on the lower side.
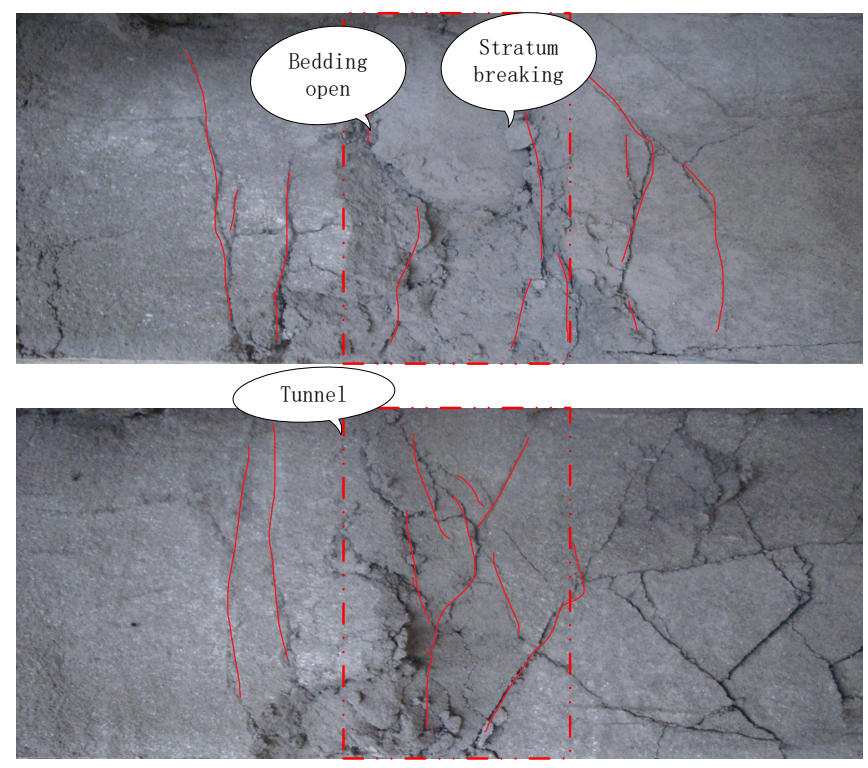

Figure 14. Floor crack development of the roadway.

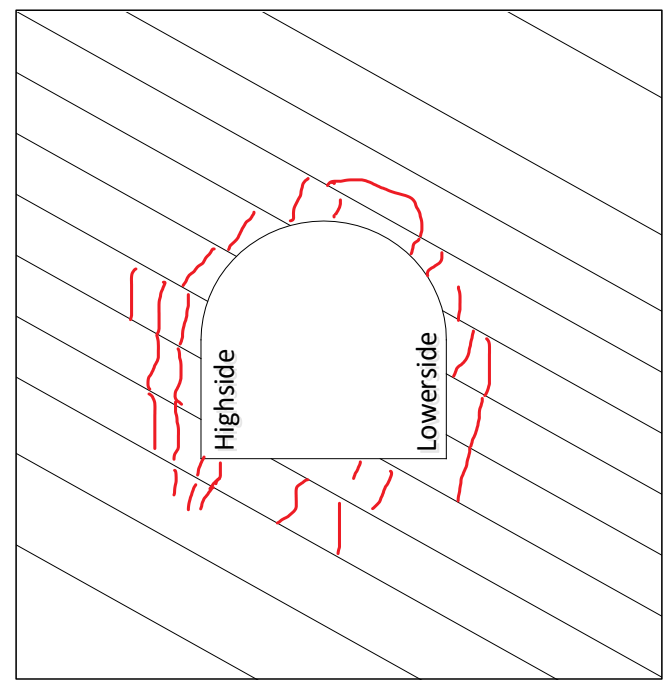

Figure 15. Crack development of the roadway-surrounding rock. 


\section{Conclusions}

The experimental results show that the experimental platform can simulate the surrounding rock stress of a deep high-stress roadway, and the obtained deformation of an inclined rock strata roadway is consistent with findings in the field.

The simulation experiment shows that the deformation of roadway-surrounding rock in deep high-stress-inclined rock strata shows obvious aging characteristics: the first is floor heave deformation, the second is roof and lower side shoulder-angle deformation, and the third is higher side shoulder-angle and lower-side deformation.

The simulation results show that the deformation of roadway-surrounding rock in deep high-stress-inclined rock strata is non-homogeneous. Deformation at the higher side below the center line and on the lower side at the shoulder angle is great. The deformation of the roof, the higher-side shoulder angle, and the lower-side center line is small. The floor heave deformation of the roadway floor is the greatest and shows obvious left-right asymmetry. The deformation of the higher side is greater than that of the lower side.

The simulation experiment shows that crack development in the surrounding rock of the roadway is non-homogeneous. The number of cracks in the higher side and bottom plate is larger, while the number of cracks in the lower side is smaller and the crack width is larger.

Author Contributions: Data curation, Q.J. and Y.Z.; Investigation, W.W.; Project administration, H.W.; Resources, N.Z. All authors have read and agreed to the published version of the manuscript.

Funding: This work was supported by the National Natural Science Foundation of China (No. 51774133, No. 52074117).

Conflicts of Interest: The authors declare no conflict of interest.

\section{References}

1. Yu, Y.; Hong, X.; Chen, F. Study on load transmission mechanism and limit equilibrium zone of coal-wall in extraction opening. J. China Coal Soc. 2012, 37, 1630-1636.

2. Zhang, B.; Cao, S.; Wang, L. Deformation Failure Mechanism and Support Measurements in Roadway of Steeply Inclined Coal Seam. J. Min. Saf. Eng. 2011, 28, 214-219.

3. Li, S.; Pan, Z.; Wang, W. Analysis of Plastic Region of Sidewalls in Coal Drifts Reinforced by Association of Rock Bolt and Grouting. J. Hunan Univ. Sci. Technol. Nat. Sci. Ed. 2007, 2, 5-8.

4. Zhang, N.; Li, B.; Li, G. Inhomogeneous damage and sealing support of roadways through thin-bedded coal-rock crossovers. J. Min. Saf. Eng. 2013, 30, 1-6.

5. Zhang, M.; Gao, J.; Wei, S. Similarity Simulation Study of Failure Characteristics ofSurrounding Rocks of Titled Strata Roadway. J. Rock Mech. Eng. 2010, 29, 3259-3264.

6. Zhang, Q.; Zhang, X.; Xiang, W. Model Test Study of Zonal Disintegration in Deep Rock mass Under Different Cavern Shapes and Loading Conditions. Chin. J. Rock Mech. Eng. 2013, 32, 1564-1571.

7. Guo, J.; Yang, Z.; Tang, H. The Effect of Lateral Pressure Coefficient on Deformation and Stress Distribution Rules AroundRoadway. J. Min. Saf. Eng. 2011, 28, 566-570.

8. Xue, D. Research on similarity simulation of soft rock entry deformation and destruction. China Coal 2010, 36, 58-61.

9. Liu, J.; Zhao, Y.; Li, P. Study of size effect of deformation of rock mass surrounding tunnel. Rock Soil Mech. 2013, 34, $2165-2173$.

10. Sun, X.; Zhang, G.; Cai, F. Asymmetric Deformation Mechanical within Inclined Rock Strata Induced by Excavation in Deep Roadway and its Controlling Countermeasures. J. Rock Mech. Eng. 2009, 28, 1137-1143.

11. Zhang, G.; He, M.; Jin, L. Deformation and Stability Lost Mechanism and Support Technology of Inclined Layer Roof in Seam Gateway. Coal Sci. Technol. 2011, 39, 1-5.

12. Bao, H.; Meng, Y.; Wu, X. Numerical Simulation of Deformation Mechanism of Deep Inclined Roadway. J. Hefei Univ. Technol. Nat. Sci. Ed. 2012, 35, 673-677.

13. Wang, W.; Feng, T. Study on Mechanism of Reinforcing Sides to Control Floor Heave of Extraction Opening. J. Rock Mech. Eng. 2005, 5, 808-811.

14. Fan, G.; Cheng, K.; Lai, X. Acoustic Emission Characteristics of Surrounding Deformation of Shield Tunnel Based on 3D Physical Similar Simulation Experiment. Saf. Coal Mines 2018, 49, 50-54.

15. Zhang, N.; Wang, X.; Kan, J. Extrusion Displacement Model and Displacement Quantization Method of Roadway Surrounding Rock. J. China Univ. Min. Technol. 2013, 42, 899-904.

16. Gao, M.; Wang, M.; Xie, J. In-situ disturbed mechanical behavior of deep coal rock. J. China Coal Soc. 2020, 45, 2691-2703. 
17. Zhang, J.; Song, Z.; Fan, W. Experimental investigation on progressive damage mechanical behavior of sandstone under true triaxial condition. J. China Coal Soc. 2019, 44, 2700-2709.

18. Yin, G.; Lu, J.; Li, X. Stability and plastic zone characteristics of surrounding rock under true triaxial stress conditions. J. China Coal Soc. 2018, 43, 2709-2717.

19. Yin, G.; Lu, J.; Li, X. Influence of intermediate principal stress on dilation and strength characteristics of sandstone. J. China Coal Soc. 2017, 42, 879-885.

20. Wang, M.; Zhu, Z.; Feng, R. Experimental study on THE failure behavior of cracked rocks around tunnels under true triaxial unloading. J. China Coal Soc. 2015, 40, 278-285.

21. Zhang, H.; Adoko, A.C.; Meng, Z. Mechanism of the Mudstone Tunnel Failures Induced by Expansive Clay Minerals. Geotech. Geol. Eng. 2017, 35, 263-275. [CrossRef]

22. Yang, X.; Wang, E.; Wang, Y. A Study of the Large Deformation Mechanism and Control Techniques for Deep Soft Rock Roadways. Sustainability 2018, 10, 1100. [CrossRef]

23. Li, M.; Zhang, J.; Quan, K. Innovative Extraction Method for a Coal Seam with a Thick Rock-Parting for Supporting Coal Mine Sustainability. Sustainability 2017, 9, 1982. [CrossRef]

24. Qin, D.; Wang, X.; Zhang, D. Study on Surrounding Rock-Bearing Structure and Associated Control Mechanism of Deep Soft Rock Roadway Under Dynamic Pressurey. Sustainability 2019, 11, 1892. [CrossRef]

25. Wu, H. Research on Asymmetrical Deformation Laws and Stability Control of Deep Inclined Rock Strata Roadway; China University of Mining and Technology: Xuzhou, China, 2014. 